\title{
Structural differences between two types of basidiomycete septal pore caps
}

\author{
Wally H. Müller, ${ }^{1,4}$ Roy C. Montijn, ${ }^{2}$ Bruno M. Humbel, ${ }^{1}$ \\ Adriaan C. van Aelst, ${ }^{3}$ Eline J. M. C. Boon, ${ }^{1}$ Theo P. van der Krift ${ }^{1}$ \\ and Teun Boekhout ${ }^{4}$
}

\footnotetext{
1 Department of Molecular Cell Biology, EMSA,

Utrecht University,

Padualaan 8 ,

$3584 \mathrm{CH}$ Utrecht

The Netherlands

2 Centre for Fungal Cell Wall Research, Institute of Molecular Cell Biology, University of Amsterdam, 1098 SM Amsterdam, The Netherlands

3 Department of Plant Cytology and Morphology, Agricultural University of Wageningen, Arboretumlaan 4, 6703 BD Wageningen, The Netherlands

4 Yeast Division of the Centraalbureau voor Schimmelcultures, Julianalaan 67 , 2628 BC Delft, The Netherlands
} Author for correspondence: Wally H. Müller (Department of Molecular Cell Biology). Tel: +31302533449.
Fax: +31 30 2513655. e-mail: W.H.Muller@bio.uu.nl

The septal pore cap (SPC) of Trichosporon sporotrichoides CBS 8245 is vesiculartubular, connected with flat-tubular endoplasmic reticulum (ER), and stains densely with zinc/iodine/osmium tetroxide, as does the ER. The SPC of Schizophyllum commune CBS 340.81 is more complex, about $600 \mathrm{~nm}$ in diameter, with perforations of 80-120 nm diameter, and stains less densely with zindiodine/osmium tetroxide than the ER. In high-pressure frozen and freeze-substituted hyphae of $T$. sporotrichoides the ER is present parallel to the dolipore septa, and electron-dense material occurs opposite the septal pore channel; the SPC rarely showed smooth vesicular-tubular membranes, suggesting that this is an ephemeral function of the SPC. The SPC of S. commune has a smooth outer and inner membrane, which enclose a matrix with a palisade-like substructure. A thin layer of electron-dense material covers the inner surface of the SPC of S. commune, from which beaded filamentous structures connect the SPC and the pore-occluding material. These filamentous structures may maintain the intracellular position of the SPC and possibly play a role in plugging the septal pore channel. The septal pore swellings of $T$. sporotrichoides contain more $1,6-\beta$-glucan than the septum, and intracellular glucans are also present near the septal pore channel. This cytosolic 1,6- $\beta$-glucan in $T$. sporotrichoides may serve as a matrix to keep the tubular membranous structures of the SPC together. In contrast, 1,6- $\beta$-glucan is not observed in the SPC and in the pore-occluding material of S. commune, and hyphal septa of this species show less labelling of 1,6- $\beta$-glucan than the septal swelling. The evolutionary transition from simple to more complex types of SPCs may have resulted in a requirement for different components to maintain the morphological integrity and cell biological function.

Keywords: $1,6-\beta$-glucan, high-pressure freezing, Schizopbyllum commune, septal pore cap, Trichosporon sporotrichoides

\section{INTRODUCTION}

The septal pore cap (SPC) or parenthesome (Bracker, 1967) occurs only in the Basidiomycota (Moore, 1985), and provides useful markers for taxonomy and phylogeny of these fungi (Tu \& Kimbrough, 1978; Khan \& Kimbrough, 1982; Van der Walt \& Von Arx, 1985; Suh et al., 1993; McLaughlin et al., 1995; Moore, 1996). The SPC was visualized for the first time by Girbardt (1958)

Abbreviations: ER, endoplasmic reticulum; PCTE, polycarbonate track etching; SPC, septal pore cap; ZIO, zinc/iodine/osmium tetroxide in Trametes versicolor (L.: Fr.) Pilát (cited as Polystictus versicolor). Since then several types of SPC have been distinguished, viz. perforate, pauciperforate, non-perforate, vesiculate, cupulate and ampullate (Khan \& Kimbrough, 1982; Moore, 1985). However, a number of basidiomycetes lack an SPC, e.g. those belonging to the Cystofilobasidium branch (Fell et al., 1995). Moreover, the SPC may disappear in some fungi following certain morphogenetic triggering, for example: during the process of conversion of dolipore septa into tapered or uniformly thick septa as observed in Coprinus lagopus (Casselton et al., 1971) and Schizophyllum commune (Marchant \& Wessels, 1974), where nuclear transport 
between neighbouring cells is facilitated; during spore maturation in Pleurotus broussonetiae Pat. (cited as Antromycopsis broussonetiae; Moore, 1977); during septal schizolysis (Tsuneda et al., 1993); in damaged hyphae of Trametes versicolor (cited as Coriolus versicolor; Aylmore et al., 1984); or in old lysed cells of Rhizoctonia solani (Butler \& Bracker, 1970).

The ultrastructure of the SPC has been elucidated to a certain extent, but its function remains largely unknown and is a matter of speculation. The perforate SPC of $R$. solani is about $1.8-2 \mu \mathrm{m}$ in diameter and has large perforations of about $600-800 \mathrm{~nm}$ diameter (Müller et al., 1998). The R. solani SPC may serve to protect the swellings of the dolipore septum during protoplasmic streaming, while allowing the passage of mitochondria and other small cell constituents (Bracker \& Butler, 1964). On the other hand, SPCs in, for example, Coprinus stercorarius, Polyporus rugulosus, Agaricus bisporus and Schizophyllum commune have smaller perforations and may act as a sieve (Wilsenach \& Kessel, 1965; Ellis et al., 1972; Thielke, 1972; Müller et al., 1994, 1995). Occluding material in the entrance of the septal pore channel may act as a valve and seems to be involved in basidiocarp formation (Flegler et al., 1976). This occluding material has a proteinaceous nature, as it can be digested by trypsin and chymotrypsin (Flegler et al., 1976). The SPC may release this proteinaceous material to plug the pore opening rapidly (Markham, 1994), suggesting a repository function for the SPC. In Pisolithus arbizus (cited as P. tinctorius), filaments occur between the inner surface of the SPC and the entrance of the septal pore channel (Orlovich \& Ashford, 1994), possibly facilitating transport of cell constituents towards the septal pore channel. The nonperforate SPC in Auricularia auricula-judae effectively controls cytosolic streaming and may prevent passage of large organelles through the septal pore channel (Lü \& McLaughlin, 1991). On the other hand, Patrignani et al. (1984) found that only septal pore channel occlusions, and not the cupulate SPC, can prevent the migration of organelles in Tremella mesenterica.

To understand the structure and function of the basidiomycete SPC, we compared the SPCs of an anamorphic yeast-like fungus, Trichosporon sporotrichoides CBS 8245 (Van Oorschot) Van Oorschot \& De Hoog (Tremellales; Fell et al., 1995) and a homobasidiomycete, Schizophyllum commune CBS 340.81 Fr.: Fr. (Schizophyllales), which belong to two different phylogenetic lineages. Several preparation methods were adopted for the electron-microscopic analysis: freeze fracturing and cytosolic maceration (Müller et al., 1994, 1995); high-pressure freezing and freeze substitution; preferential staining of the endoplasmic reticulum (ER) and the SPC with zinc/iodine/osmium tetroxide (ZIO) (Hawes, 1991); sugar staining with alkaline bismuth (Shinji et al., 1975, 1976); and immunogold labelling of $1,6-\beta$-glucan. In addition, the SPCs of $S$. commune were studied in protoplasts. This combined approach has shown marked differences between the two types of SPC and resulted in a more complete picture of these SPCs.

\section{METHODS}

Strains, media and culture conditions. Trichosporon sporotrichoides strain CBS 8245 and Schizophyllum commune strain CBS 340.81 were maintained on YPGA $(0.3 \%, w / v$, yeast extract, $0.5 \%, \mathrm{w} / \mathrm{v}$, peptone, $1 \%$, w $/ \mathrm{v}$, glucose, $2 \%, \mathrm{w} / \mathrm{v}$, agar) at $10^{\circ} \mathrm{C}$. Hyphal cells were scraped from a slant culture and grown for $3 \mathrm{~d}$ at room temperature between two polycarbonate track etching (PCTE) filters (Poretics; $0.6 \mu \mathrm{m}$ pore size, $37 \mathrm{~mm}$ filter size) as described by Wösten et al. (1991).

Scanning electron microscopy. Colonies grown between PCTE filters were fixed in $2 \%(\mathrm{v} / \mathrm{v})$ glutaraldehyde (EM grade $8 \%$; Polysciences) in $50 \mathrm{mM}$ sodium cacodylate buffer, $\mathrm{pH}$ $7 \cdot 4$, for $16 \mathrm{~h}$ at $4{ }^{\circ} \mathrm{C}$. The fixed samples were postfixed with $1 \%(\mathrm{w} / \mathrm{v})$ osmium tetroxide buffered with $66 \mathrm{mM}$ phosphate buffer, $\mathrm{pH} 7 \cdot 4$, for $16 \mathrm{~h}$ at $4^{\circ} \mathrm{C}$. Freeze-fracturing, cytosolic maceration and further processing for scanning electron microscopy were done as described by Müller et al. (1994). The platinum-coated fungal fragments were examined in a field-emission scanning electron microscope (JSM 6300F, JEOL) at an acceleration voltage of $7 \mathrm{kV}$.

High-pressure freezing and freeze substitution. Peripheral mycelial parts of colonies cultured between PCTE filters were placed in specimen holders with 1-hexadecene (Müller \& Moor, 1984; Studer et al., 1995) and subsequently frozen in a high-pressure freezer (Leica EM HPF) and used for freeze substitution. Hyphal material was transferred in liquid nitrogen to a CS auto-substitution chamber (Reichert-Jung) at $-90{ }^{\circ} \mathrm{C}$ containing a mixture of $1 \%(\mathrm{w} / \mathrm{v})$ osmium tetroxide, $3 \%(\mathrm{v} / \mathrm{v})$ glutaraldehyde and $0.5 \%(\mathrm{w} / \mathrm{v})$ uranyl acetate in methanol (complex freeze-substitution medium) according to Müller et al. (1980) For immunogold labelling, the substitution chamber contained a mixture of $0.2 \%(\mathrm{w} / \mathrm{v})$ uranyl acetate and $0.01 \%(\mathrm{v} / \mathrm{v})$ glutaraldehyde in methanol. After $5 \mathrm{~d}$, the temperature was raised from $-90^{\circ} \mathrm{C}$ to $4{ }^{\circ} \mathrm{C}$ (for immunogold labelling, to $-40^{\circ} \mathrm{C}$ ) at a rate of $10^{\circ} \mathrm{C} \mathrm{h}^{-1}$, for low temperature embedding and further processing with Lowicryl HM20 (Müller et al., 1991). Specimens substituted with complex freeze-substitution medium were rinsed with methanol, followed by anhydrous acetone. After raising the temperature to room temperature, the specimens were infiltrated and embedded with Spurr's resin (Spurr, 1969), and polymerized for $24 \mathrm{~h}$ at $60^{\circ} \mathrm{C}$. Sections $(80 \mathrm{~nm})$ of hyphae substituted in complex freeze-substitution medium were mounted on $1.1 \%(\mathrm{w} / \mathrm{v}$ ) pioloform and carbon-coated singlehole copper grids, dried for $16 \mathrm{~h}$, and stained with $3 \%(\mathrm{w} / \mathrm{v})$ aqueous uranyl acetate for $45 \mathrm{~min}$ and with lead citrate for 8 min, according to Venable \& Coggeshall (1965).

Preferential staining. Colonies cultured between PCTE filters were fixed in $3 \%(\mathrm{v} / \mathrm{v})$ glutaraldehyde (EM grade $8 \%$; Polysciences) buffered with $50 \mathrm{mM}$ sodium cacodylate buffer, $\mathrm{pH} 7 \cdot 4$, for $1 \mathrm{~h}$ on ice. After washing in the sodium cacodylate buffer and in distilled water, the colonies were immersed in unbuffered ZIO for $3 \mathrm{~h}$ at $37^{\circ} \mathrm{C}$ (Hawes, 1991). The ZIOstained hyphae were processed further as described by Müller et al. (1995).

Sugar staining. After freeze substitution, embedding in Spurr's resin, ultramicrotomy and polymerization, the $80 \mathrm{~nm}$ sections of hyphal material were stained with alkaline bismuth for $3 \mathrm{~h}$ at $37^{\circ} \mathrm{C}$ according to Shinji et al. (1975).

Immunogold labelling of $\mathbf{1 , 6} \boldsymbol{\beta} \boldsymbol{\beta}$-glucan. Lowicryl HM20 sections of hyphal material were incubated with affinitypurified polyclonal antibodies $\left(1.66 \mu \mathrm{g} \mathrm{ml}^{-1}\right)$ recognizing $1,6-\beta-$ 

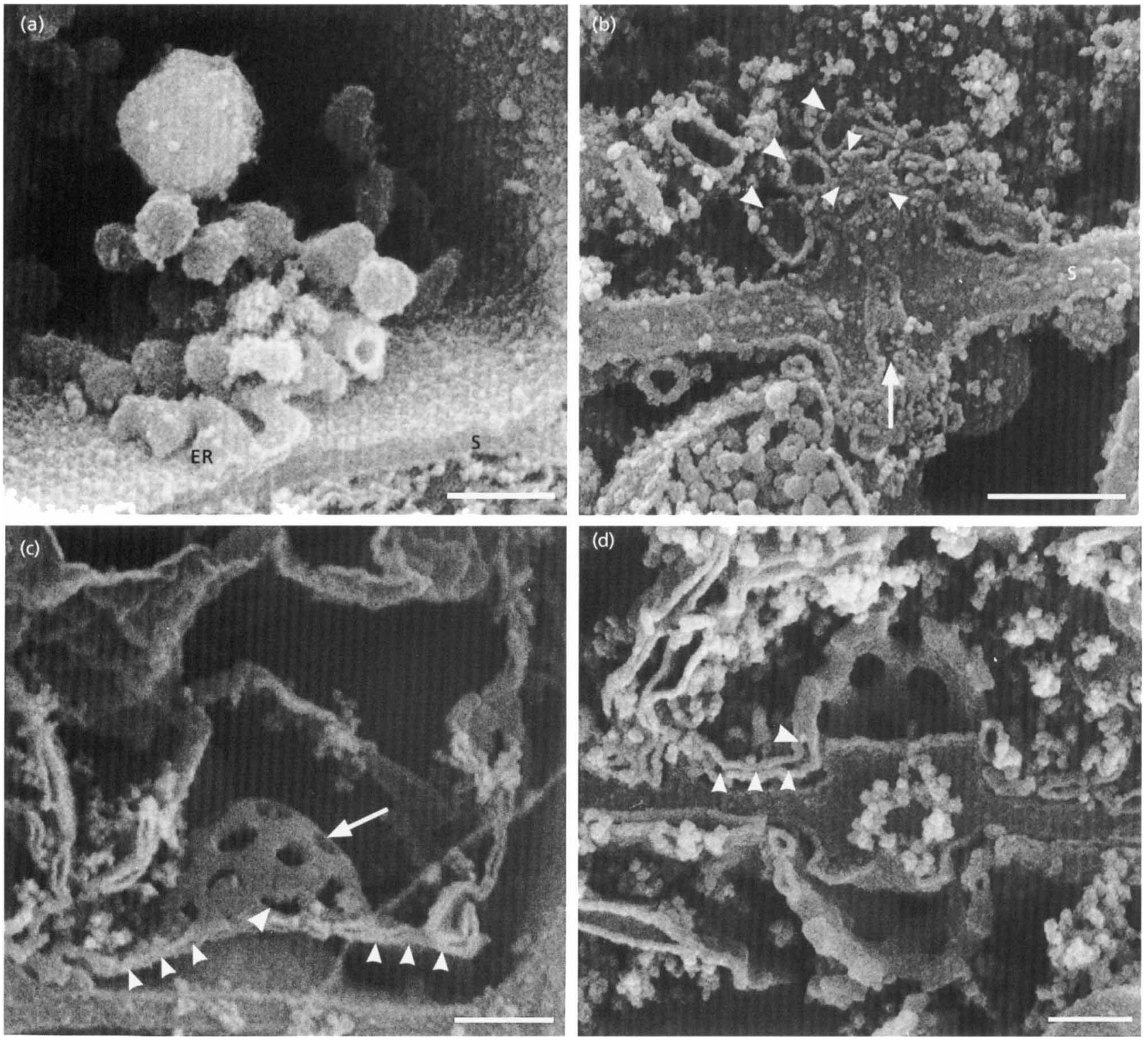

Fig. 1. Scanning electron micrographs of hyphae of $T$. sporotrichoides CBS 8245 and $S$. commune 340.81 revealing the intracellular organization. (a) Side view of an SPC of $T$. sporotrichoides CBS 8245, which consists of smooth vesiculartubular membranous structures. The septum (S) is cross-fractured and a remnant of ER is connected to a tubular structure of the SPC. (b) Part of a longitudinally fractured hypha of $T$. sporotrichoides at the position of a septal pore channel (arrow), which is covered by the SPC. The smooth tubular structures are cross-fractured. The small tubular structures (small arrowheads) have a diameter of $30-40 \mathrm{~nm}$ and are located between the inflations of the dolipore septum, and the larger ones (large arrowheads) have a diameter of $80-120 \mathrm{~nm}$. (c) Side view of a perforate SPC (arrow) of S. commune with different hole diameters. Plate-like ER is connected to the SPC (small arrowheads). In the connection area of the ER and the SPC, irregularly shaped holes are present (large arrowhead). (d) Part of a longitudinally fractured S. commune hypha with perforate SPCs on either side of the dolipore septum. The figure clearly shows the connection (large arrowhead) of plate-like ER (small arrowheads) to the basal part of the SPC. Bars, $250 \mathrm{~nm}$.

glucan (Montijn et al., 1994; Lu et al., 1995). The antigenantibody complexes were visualized with goat anti-rabbit antibodies $\left(1 \mu \mathrm{g} \mathrm{ml}^{-1}\right)$ conjugated with $10 \mathrm{~nm}$ gold particles $\left(5 \times 10^{12}\right.$ particles $\mathrm{ml}^{-1}$; Aurion).

Formation of $S$. commune protoplasts. Twenty-five millilitres of protoplasting medium $\left(2 \mathrm{~g}\right.$ citric acid $\mathrm{l}^{-1}, 0.5 \mathrm{M} \mathrm{MgSO}_{4}$, pH 5.8, set with Tris; De Vries \& Wessels, 1972) and $250 \mathrm{mg}$ Novozym 234 (Novo) were added to $5 \mathrm{~g}$ (wet weight) hyphae and incubated in a shaker incubator at 100 r.p.m. for $4 \mathrm{~h}$ at $30^{\circ} \mathrm{C}$. Protoplast formation was checked by light microscopy every $30 \mathrm{~min}$. After $4 \mathrm{~h}$, the protoplasts were collected in a $50 \mathrm{ml}$ Falcon centrifuge tube (Becton Dickinson Labware) and centrifuged at $300 \mathrm{~g}$ for $10 \mathrm{~min}$. The supernatant was centrifuged at $14000 \mathrm{~g}$ in a Sorvall RC-5 Superspeed Refrigerated Centrifuge (DuPont Instruments) for $45 \mathrm{~min}$ at $4^{\circ} \mathrm{C}$. The volume of the $14000 \mathrm{~g}$ pellet was about $2 \mathrm{ml}$ and contained about $8 \times 10^{7}$ protoplasts. These protoplasts were chemically fixed with $2 \%$ (v/v) glutaraldehyde in $\mathrm{MgSO}_{4}$ buffer $(2 \mathrm{~g}$ citric 

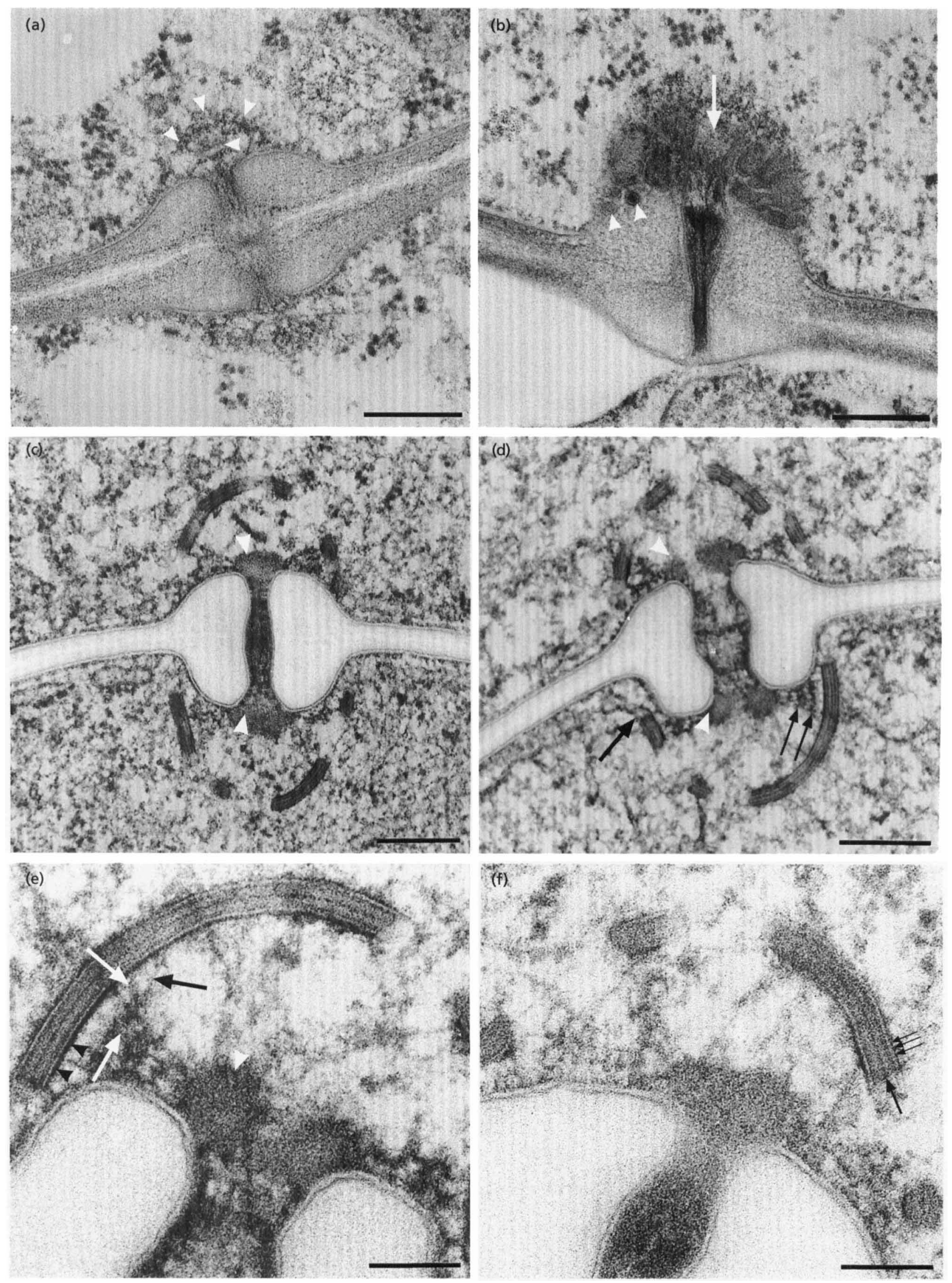

Fig. 2. For legend see facing page. 
acid $1^{-1}, 0.5 \mathrm{M} \mathrm{MgSO}_{4}$, pH 5.8, set with Tris) for $30 \mathrm{~min}$, washed twice with $\mathrm{MgSO}_{4}$ buffer and postfixed with $1 \%$ (w/v) osmium tetroxide in $\mathrm{MgSO}_{4}$ buffer for $1 \mathrm{~h}$. The protoplasts were washed twice with $\mathrm{MgSO}_{4}$ buffer and three times with distilled water. The protoplasts were embedded in $2 \%(\mathrm{w} / \mathrm{v})$ low-melting-point agar (type VII low-gelling temperature; Sigma). Blocks of about $2 \mathrm{~mm}^{3}$ were cut with a razor blade and dehydrated through a series of $50 \%$ to $100 \%$ acetone. After a step in acetone + dimethoxypropane $[1 \mathrm{ml}$ acidic dimethoxypropane (four drops $37 \% \mathrm{HCl}$ in $50 \mathrm{ml}$ dimethoxypropane), $100 \mathrm{ml}$ acetone], the material was infiltrated and embedded in Spurr's resin (Spurr, 1969), polymerized for $16 \mathrm{~h}$ at $65^{\circ} \mathrm{C}$, cut into $80 \mathrm{~nm}$ sections with a Diatome diamond knife on a Reichert Jung Ultracut E ultramicrotome and picked up on 150 mesh copper grids. The grids had been covered with a Formvar film $(1 \%, \mathrm{w} / \mathrm{v}$, Formvar in chloroform) and carbon coated. The sections were stained for $10 \mathrm{~min}$ with $4 \%(\mathrm{w} / \mathrm{v})$ uranyl acetate, followed by $90 \mathrm{~s}$ with $2.66 \%$ (w/v) lead citrate (Reynolds, 1963).

Transmission electron microscopy. Sections were viewed in a Philips EM420 electron microscope. Micrographs of the SPC were taken at an acceleration voltage of $80 \mathrm{kV}$.

\section{RESULTS}

\section{Scanning electron microscopy of the SPC}

Longitudinal fracturing and subsequent processing revealed the intracellular organization of hyphal cells of $T$. sporotrichoides CBS 8245 and S. commune CBS 340.81. In T. sporotrichoides, an aggregate of tubular, globular and sausage-shaped membranous structures covered the dolipore septum (Fig. 1a), forming an SPC. These structures were connected to flat-tubular ER. In median fractures, the SPC consisted of cross-fractured smooth tubular membranous structures varying in width between 40 and $120 \mathrm{~nm}$ (Fig. 1b). The smaller tubular structures were located between the larger ones and the rounded inflations of the dolipore (Fig. 1b). The SPC of $S$. commune revealed round, or ellipsoid, apical perforations of $110-120 \mathrm{~nm}$ diameter, and smaller basal perforations of about $80 \mathrm{~nm}$ diameter. The SPC was connected to plate-like ER, and irregularly shaped holes were present in the connection area (Fig. 1c). A near-
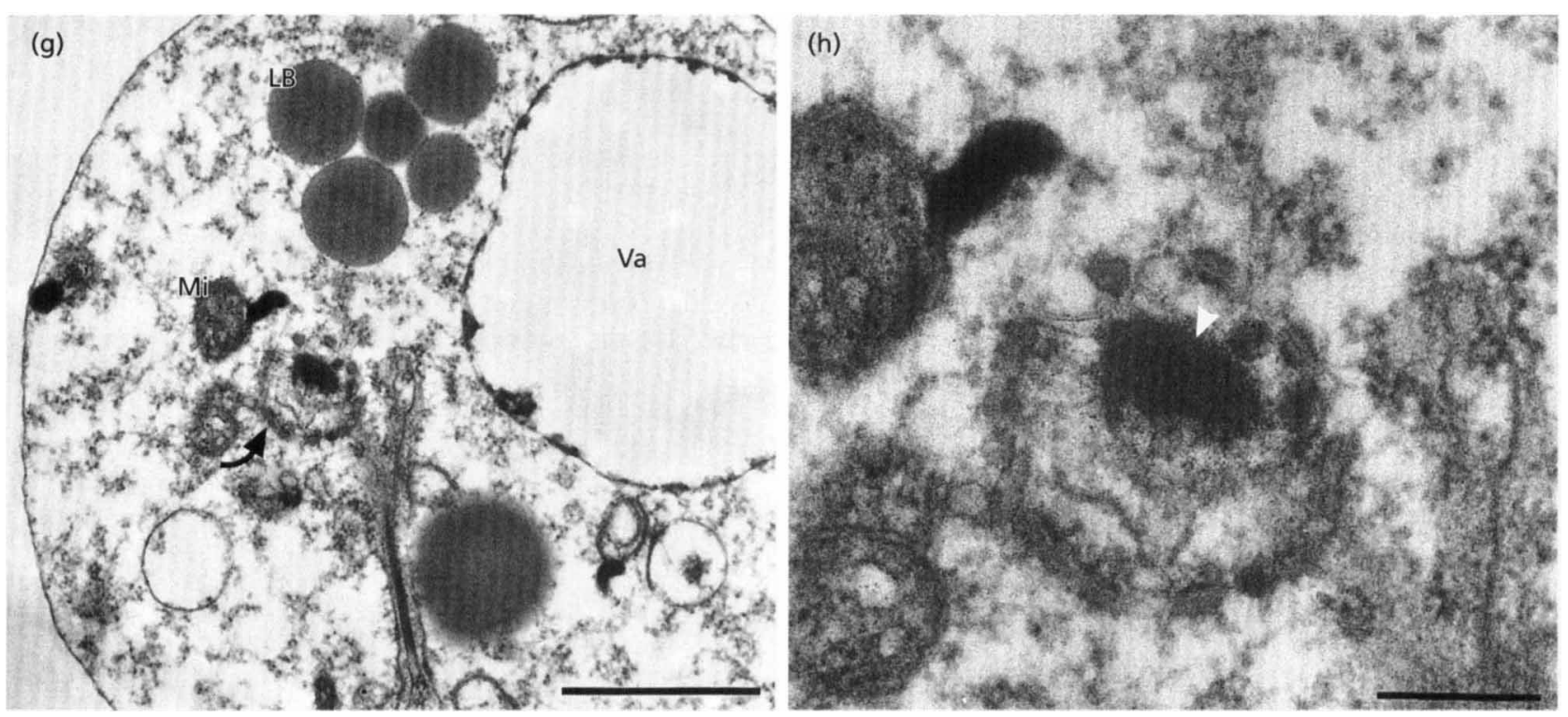

Fig. 2. High-pressure freezing and freeze substitution of hyphae of $T$. sporotrichoides CBS 8245 (a, b) and $S$. commune CBS 340.81 ( $c$, d, e, f) showing the SPC as it occurs in situ, and the SPC in an S. commune protoplast after conventional chemical fixation $(g, h)$. (a) Part of a $T$. sporotrichoides hypha showing no SPC but electron-dense material opposite the septal pore channel (small arrowheads). Bar, $250 \mathrm{~nm}$. (b) Obliquely sectioned vesicular-tubular structures of the SPC of $T$. sporotrichoides. The septal pore channel appears to be open at the tubular side (arrow). Small membranous structures are present in the septal swelling (arrowheads). Bar, $250 \mathrm{~nm}$. (c) Perforate SPC of S. commune on either side of the dolipore septum. The septal pore channel is closed by electron-dense occluding material (arrowheads). Bar, $250 \mathrm{~nm}$. (d) A perforate SPC of S. commune on either side of an open septal pore channel. Occluding materials (arrowheads) appear to be connected to beaded filamentous structures (small arrows). The plate-like ER is connected to the basal part of the perforate SPC (arrow). In the mid-point of the septal pore channel, a transverse line of electron-dense material separates electron-dense material of fluffy appearance. Bar, $250 \mathrm{~nm}$. (e) Higher magnification of (d). A thin layer of electron-dense material (small arrowheads) covers the inner side of the SPC. Beaded filamentous structures (arrows) connect the inner side of the SPC with plug material (large arrowhead). Bar, $100 \mathrm{~nm}$. (f) Higher magnification of a perforate SPC of S. commune, showing a layered structure. Two unit membranes confine SPC matrix material, which is separated by a thin electron-dense line (vertical arrow) and is made up of small palisade-like structures (horizontal arrows). Bar, $100 \mathrm{~nm}$ (g) $S$. commune protoplast after chemical fixation showing that the structural relationships of the SPC appear to be intact. Besides the SPC (arrow), other organelles like a mitochondrion (Mi), a vacuole (Va) and lipid bodies (LB) are present. Bar, $1 \mu \mathrm{m}$. (h) Higher magnification of the SPC shown in (g). The perforate SPC confines occluding material (arrowhead). Bar, $250 \mathrm{~nm}$. 

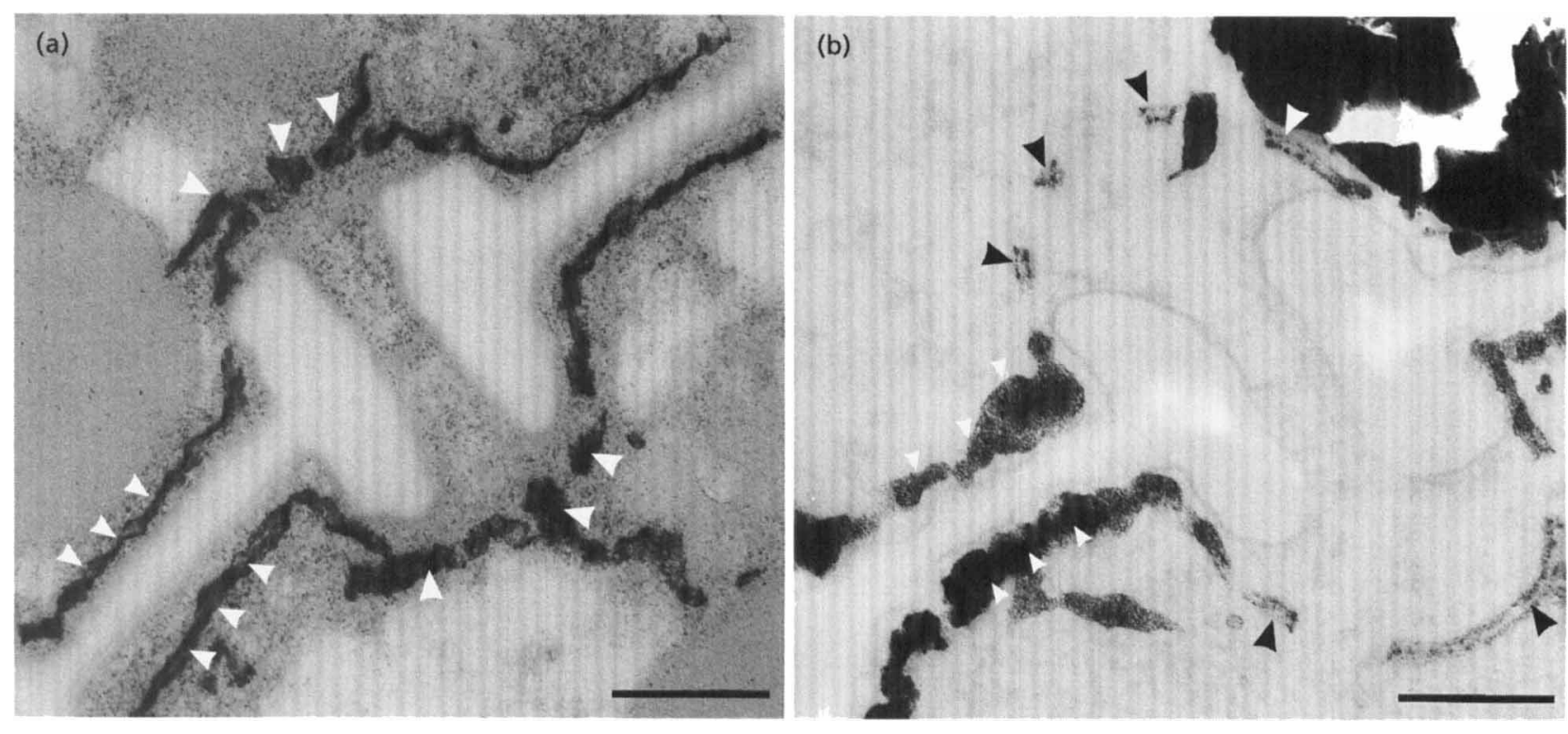

Fig. 3. ZIO staining of the ER and the SPC in T. sporotrichoides CBS 8245 and S. commune CBS 340.81 . (a) The ER (small arrowheads) parallel to the septum is connected to the SPC (large arrowheads) of $T$. sporotrichoides. The SPC is as densely stained as the ER. Bar, $250 \mathrm{~nm}$. (b) Only the unit membranes (large arrowheads) of the SPC of S. commune and the ER (small arrowheads) are densely stained. Bar, $250 \mathrm{~nm}$.

median fracture of an $S$. commune hyphal cell clearly showed that the perforations in the cap were smaller than mitochondria, which measured $300 \mu \mathrm{m}$ in diameter, and vacuoles, while the ribosomes were small enough to easily pass through the SPC (Fig. 1d).

\section{Transmission electron microscopy of the SPC}

In most observations after high-pressure freezing, freeze substitution and longitudinal sectioning, the dolipore of T. sporotrichoides lacked an SPC. In T. sporotrichoides, electron-dense material was present near the opening and the mid-point of the septal pore channel (Fig. 2a). The septal pore channel contained longitudinal fibrils. Only rarely, vesicular-tubular membranous structures formed an SPC in T. sporotrichoides hyphae (Fig. 2b). Also, small membranous structures were present in the annular swelling (Fig. 2b). As observed by scanning electron microscopy, the smallest vesicular-tubular structures of the SPC were situated between the larger ones and the septal swelling. The vesicular-tubular SPC of $T$. sporotrichoides contained electron-dense material. The septal pore channel had a connection with the cytosol and contained more electron-dense material in its mid-region than at its entrance (Fig. 2b). In $S$. commune, the SPC was always present. Pore-occluding material blocked the septal pore channel (Fig. 2c); when the channel was open, a ring of electron-dense material was present (Fig. 2d) and the channel was about twice as wide as when closed. Electron-dense material filled the closed septal pore channels, and was located at the midpoint of the open septal pore channel (Fig. $2 \mathrm{~d}$ ). The SPC was connected to plate-like ER (Fig. 2d) and consisted of an outer and an inner membrane, enclosing a matrix (Fig. 2e, f). In this matrix, palisade-like structures were often present (Fig. 2f). A thin layer of electron-dense material covered the inner surface of the SPC (Fig. 2e, f) and beaded, electron-dense, filamentous structures connected this inner surface of the SPC to the pore-occluding material (Fig. 2d, e, f). Based on the intactness and the regular appearance of the beaded-filamentous structures, these structures appeared to reflect the in vivo situation after cryofixation and freeze substitution. The filamentous structures were best observed when the septal pore channel was not completely occluded (Fig. $2 \mathrm{~d}, \mathrm{e})$.

In sections, five out of 100 protoplasts of $S$. commune showed an SPC (Fig. 2g, h) and the SPC ultrastructure remained intact. The SPC contained putative remnants of the pore-occluding material.

In hyphae of $T$. sporotrichoides and $S$. commune, the connection of the ER to the SPC was clearly visible after ZIO staining, indicating the presence of calcium affinity sites (Gilloteaux \& Naud, 1979). In T. sporotrichoides, the ER near the dolipore septum was continuous with the aggregate of membranous vesicular-tubular structures that formed the SPC. This simple SPC was as densely stained as the ER (Fig. 3a). In S. commune (Fig. $3 \mathrm{~b}$ ), only the outer and the inner membranes of the SPC and the ER lumen were electron-dense.

Polysaccharides with 1,2-glycol groups like glucan and mannan can be stained with alkaline bismuth (Shinji et al., 1975, 1976). After alkaline bismuth staining, $T$. sporotrichoides hyphae showed a more densely stained dolipore swelling than the septum (Fig. 4a), while in $S$. 

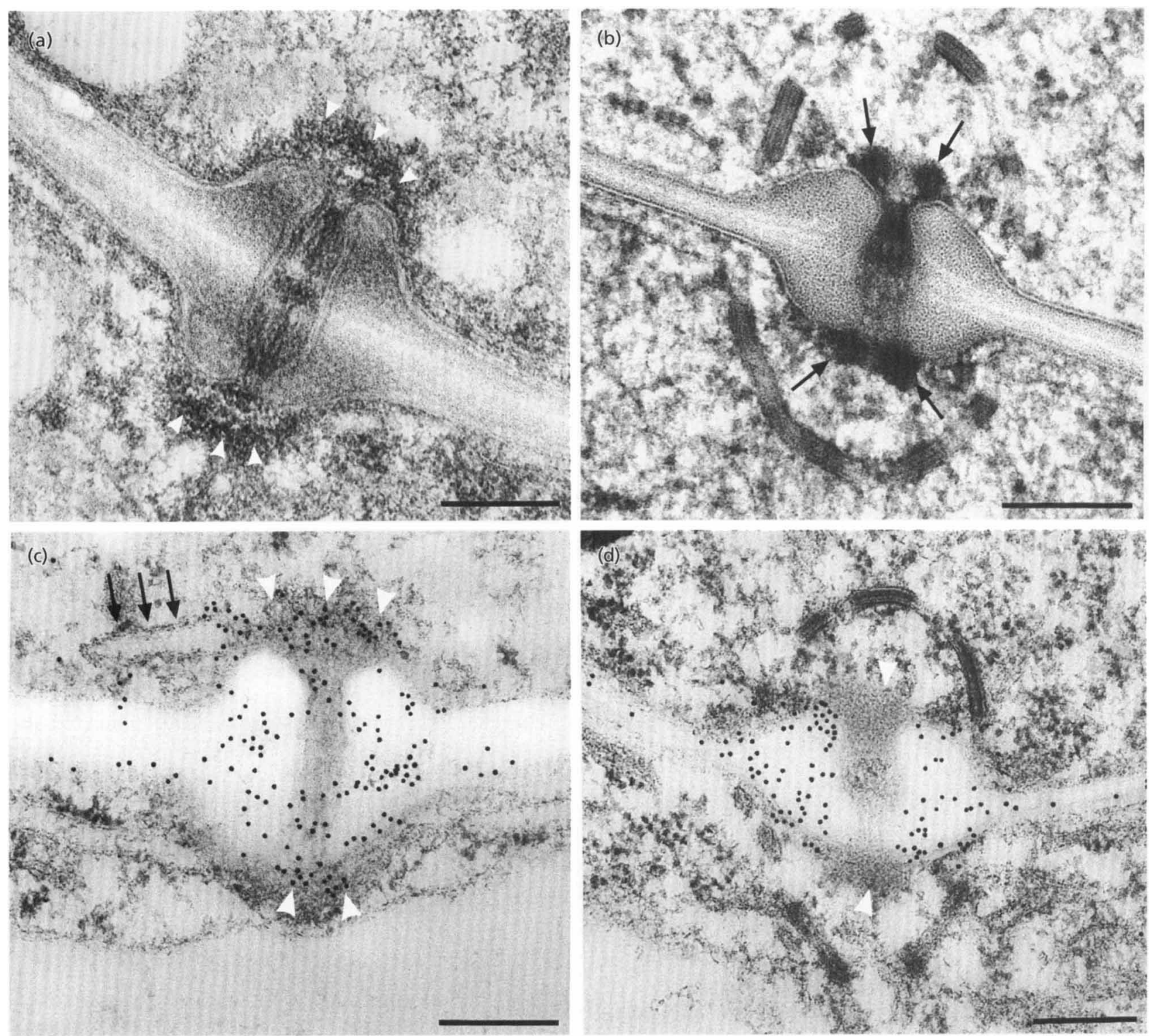

Fig. 4. Alkaline bismuth staining and immunogold labelling of sugar components in hyphae of $T$. sporotrichoides CBS 8245 and S. commune CBS 340.81. (a) Part of a hypha of $T$. sporotrichoides with electron-dense alkaline bismuth staining of the swelling of the septum and electron-dense material opposite the septal pore channel (arrowheads). (b) In S. commune, except for the central chitin plate, the dolipore septum is equally electron-dense. The occluding material (arrows) is also stained. (c) Location of 1,6- $\beta$-glucan in $T$. sporotrichoides. The septal swelling and the cytosolic electrondense material (arrowheads) are abundantly labelled with gold particles. Arrows indicate the ER. (d) Location of 1,6- $\beta$ glucan in $S$. commune. The septal swelling is abundantly labelled with gold particles. No gold particles are located in the occluding material (arrowheads). Bars, $250 \mathrm{~nm}$.

commune, all wall structures except the central chitin plate appeared equally electron-dense (Fig. 4b). Electron-dense material was present at the entrance and in the septal pore channel of T. sporotrichoides (Fig. 4a), whereas in $S$. commune the pore-occluding material gave a more electron-dense staining than the septum (Fig. 4b).

Immunogold labelling of 1,6- $\beta$-glucan showed clear differences between the SPCs of the two species. The dolipore swelling in $T$. sporotrichoides was more intensely labelled with gold particles than the remainder of the septum (Fig. 4c), which agreed with our alkaline bismuth staining results. The dolipore swelling of $S$. commune was more densely labelled with gold particles than the septum (Fig. 4d). Gold particles in the occluding material at both sides of the septal pore channel in $T$. sporotrichoides indicated the presence of cytosolic 1,6$\beta$-glucan in this species (Fig. 4c), whereas in S. commune neither the SPC nor the occluding material was gold labelled (Fig. $4 \mathrm{~d}$ ), indicating the lack of $1,6-\beta$-glucan in these subcellular structures. 


\section{DISCUSSION}

The structure of the SPC differs among the evolutionary lineages of the Basidiomycota. As we have shown, the SPC of T. sporotrichoides CBS 8245 consists of smooth vesicular-tubular membranous structures and a supporting electron-dense layer containing $1,6-\beta$-glucan. In cell walls of Saccharomyces cerevisiae, $1,6-\beta$-glucan has a cross-linking function, thus increasing cell wall rigidity (Kapteyn et al., 1994, 1996). We hypothesize that the cytosolic 1,6- $\beta$-glucan-containing layer opposite the entrance of the septal pore channel of T. sporotrichoides may act as a matrix to keep the membranous structures together, thus forming a simple SPC. In addition, 1,6- $\beta$ glucan in the cell wall may support the rigidity of the septal swellings in hyphae with either simple or more complex SPCs.

$1,6-\beta$-Glucan was not detected in the SPC or in the poreoccluding material of $S$. commune. The integrity of the SPC after protoplast formation suggests that this structure is internally rigid. We favour a role of the filamentous structures connecting the inner surface of the SPC and the pore-occluding material to maintain the intracellular position of the SPC in S. commune hyphae. In Pisolithus arbizus, similar filamentous structures are thought to anchor the base of the SPC to the dolipore swelling, to maintain its shape and to guide the movement of cytosolic streams (Orlovich \& Ashford, 1994). A possible alternative function of these filamentous structures in maintaining the shape of the cap, as proposed by these authors, seems to be unlikely as we showed that free-lying SPCs in S. commune protoplasts maintained their dome shape, and, after scanning electron microscopy, these SPCs did not reveal any filamentous structures. Therefore, maintenance of the shape of the SPC in $S$. commune hyphae may be solely accomplished by its matrix, which is made up of palisade-like structures of unknown composition, as was also described in the SPC matrix of Pleurotus cystidiosus (Moore \& Patton, 1975).

The filamentous structures connecting the SPC with the pore-occluding material may also play a role in plugging the entrance of the septal pore channel, thus regulating intercellular communication (Flegler et al., 1976, Orlovich \& Ashford, 1994). Plugged septal pore channels of $S$. commune are narrower than non-plugged ones. The transverse electron-dense material at the midpoint of the septal pore channel of $S$. commune is probably involved in the dynamics of opening and closing the septal pore channel. In T. sporotrichoides the filamentous structures connecting the SPC and the occluding material were not observed, indicating that the process of plugging must be different in this species.

The plug may originate from the cytosol (Aylmore et al., 1984) or from the SPC (Markham, 1994). We hypothesize that the ER may be another repository of the plug, as the ER is connected to the occluding material via the SPC and the filamentous structures. Consequently, precursors of the occluding material may be synthesized elsewhere in the cell or in the ER, then processed in the ER, transported through the ER to the SPC and subsequently relocated through the inner membrane of the SPC. The processed precursors could be transported, via the filamentous structures, to the entrance of the septal pore channel to form a plug, probably with other components from the cytosol.

In T. sporotrichoides, the SPC and the ER did not show differences in ZIO deposits, while in S. commune only the inner and the outer membranes of the SPC and the ER showed ZIO deposits. ZIO-stained SPCs were also reported in the agaric Amanita rubescens (Hawes, 1981). This suggests that there is no structural or functional differentiation between the SPC and the ER in $T$. sporotrichoides, whereas the SPC of S. commune may be functionally different from the ER. As ZIO stains calcium-affinity sites (Gilloteaux \& Naud, 1979), the ER of $S$. commune and the ER as well as the SPC of T. sporotrichoides may act as a sink for calcium ions, which may play an important role in cell signalling (Sitia \& Meldolesi, 1992).

ZIO staining in ascogenous hyphae of Sordaria humana showed the continuity between the ER and the complex septal pore structures (Beckett, 1981; Read \& Beckett, 1996), consisting of multilayered membranes from which membranous cisternae arise. No differences in ZIO deposits were observed between the ER and the cisternae. This is similar to the ER connected to the simple SPC in $T$. sporotrichoides. Therefore, there may be no difference between the calcium-affinity sites, as detected by ZIO staining (Gilloteaux \& Naud, 1979), in the complex septal pore structures of the ascogenous hyphae of $S$. bumana, and the calcium affinity sites present in the ER and the simple SPC of the basidiomycetous hyphae of $T$. sporotrichoides. In contrast, the presence of calcium-affinity sites seems to differ between the ER and the more complex SPC of S. commune.

With the scanning electron microscope, plate-like ER along the septum is seen in monokaryotic hyphae of $S$. commune, while the ER is tubular in dikaryotic hyphae (Müller et al., 1994). Although septa of dikaryotic hyphae were found to be much more resistant to enzymic dissolution than those of monokaryotic hyphae of $S$. commune (Casselton et al., 1971; Wessels \& Marchant, 1974), the function of the different types of ER observed in these hyphae remains unclear.

The ultrastructure of the SPC of T. sporotrichoides and $S$. commune has been repeatedly studied after chemical fixation (e.g. Guého et al., 1992; Jersild et al., 1967; Mayfield, 1974; Moore \& Patton, 1975; Van der Valk et al., 1977). Guého et al. (1992) reported that the SPC was almost absent in T. sporotrichoides and was present only as remnants of ER opposite the entrance of the septal pore channel. However, we have shown that a simple SPC exists in this species, consisting of smooth vesicular-tubular membranous structures. As this simple SPC was only rarely observed, this SPC may occur in $T$. sporotrichoides only during certain developmental stages. Although the morphology of the SPC is better preserved by the combined use of cryofixation and 
freeze substitution (e.g. Hoch \& Howard, 1981; Howard \& O’Donnell, 1987; Lü \& McLaughlin, 1991; Orlovich \& Ashford, 1994), ZIO staining, freezefracturing and cytosolic maceration may show other details of the SPC which cannot be seen after cryofixation and freeze substitution. We favour a combination of different preparation methods for electron microscopy to obtain a more complete picture of the SPC.

The ultrastructure and function of the SPC are still under debate. As the membranes of the $S$. commune SPC enclose a layered matrix, this raises the following questions: how are the matrix layers deposited, and what is the biochemical nature of the matrix? Answers to these questions will contribute to the understanding of the function of the SPC. Also, detailed comparative and functional studies of other types of SPC among the basidiomycetes may provide clues to their function and phylogenetic importance. The evolutionary change from the putatively simple SPC of $T$. sporotrichoides to the more complex SPC present in higher basidiomycetes may be the result of structural adaptations to a changed function. In this view, the function of the SPC is strongly correlated with its morphology (Ellis et al., 1972) or its location in the hyphal filament (Patrignani et al., 1984). It is most likely that the SPC is involved in cell-cell contact and maintaining homeostasis.

The results of our combined studies suggest that different components are required to maintain the integrity of the SPC in basidiomycetes belonging to different phylogenetic lineages. This may be accomplished by the presence of cytosolic $1,6-\beta$-glucan, the direct connection of the SPC with the ER, the differentiation between the SPC and the ER with respect to calcium-binding sites, or the occurrence of a distinct SPC matrix enclosed by an outer and an inner membrane. Moreover, we propose a role of the beaded filamentous structures in transport of cytosolic components to form a plug.

\section{ACKNOWLEDGEMENTS}

We thank Professor Dr W. Gams and Dr D. van der Mei (Centraalbureau voor Schimmelcultures, Baarn, NL) for critical reading of the manuscript; $H$. Kieft (Agricultural University of Wageningen, Wageningen, NL) for transporting the JEOL scanning electron microscopical images with the file transport protocol; Professor Dr A. J. Verkleij (Utrecht University, Utrecht, NL) for fruitful discussions; and Miss L. Verspui (Utrecht University) for the preparation of the photographs. This work is based on a co-operative project between the Centraalbureau voor Schimmelcultures and Utrecht University.

\section{REFERENCES}

Aylmore, R. C., Wakley, G. E. \& Todd, N. K. (1984). Septal sealing in the basidiomycete Coriolus versicolor. J Gen Microbiol 130, 2975-2982.

Beckett, A. (1981). The ultrastructure of septal pores and associated structures in ascogenous hyphae and asci of Sordaria bumana. Protoplasma 107, 127-147.
Bracker, C. E. (1967). Ultrastructure of fungi. Annu Rev Phytopathol 5, 343-374.

Bracker, C. E. \& Butler, E. E. (1964). Function of the septal pore apparatus in Rizoctonia solani during protoplasmic streaming. $J$ Cell Biol 21, 152-157.

Butler, E. E. \& Bracker, C. E. (1970). Morphology and cytology of Rhizoctonia solani. In Rhizoctonia solani, Biology and Pathology, pp. 32-51. Edited by J. R. Parmeter. Los Angeles: University of California Press.

Casselton, L. A., Lewis, D. \& Marchant, R. (1971). Septal structure and mating behaviour of common $A$ diploid strains of Coprinus lagopus. J Gen Microbiol 66, 273-278.

De Vries, O. M. H. \& Wessels, J. G. H. (1972). Release of protoplasts from Schizophyllum commune by a lytic enzyme preparation from Trichoderma viride. J Gen Microbiol 73, 13-22.

Ellis, T. T., Rogers, M. A. \& Mims, C. W. (1972). The fine structure of the septal pore cap in Coprinus stercorarius. Mycologia 64, $681-688$.

Fell, J. W., Boekhout, T. \& Freshwater, D. W. (1995). The role of nucleotide sequence analysis in the systematics of the yeast genera Cryptococcus and Rbodotorula. Stud Mycol 38, 129-146.

Flegler, S. L., Hooper, G. R. \& Fields, W. G. (1976). Ultrastructural and cytochemical changes in the basidiomycete dolipore septum associated with fruiting. Can J Bot 54, 2243-2253.

Gilloteaux, J. \& Naud, J. (1979). The zinc iodide-osmium tetroxide staining of Maillet. $\mathrm{Ca}^{2+}$-affinity subcellular sites in a tonic smooth muscle. Histochemistry 63, 227-243.

Girbardt, M. (1958). Über die Substruktur von Polystictus versicolor L. Arch Mikrobiol 28, 255-269.

Guého, E., Smith, M. Th., De Hoog, G. S., Billon-Grand, G., Christen, R. \& Batenburg-Van der Vegte, W. H. (1992). Contributions to a revision of the genus Trichosporon. Antonie Leeuwenhoek 61, 289-316.

Hawes, C. R. (1981). Applications of high-voltage electron microscopy to botanical ultrastructure. Micron 12, 227-257.

Hawes, C. R. (1991). Stereo-electron microscopy. In Electron Microscopy of Plant Cells, pp. 67-84. Edited by J. L. Hall \& C. Hawes. London: Academic Press.

Hoch, H. C. \& Howard, R. J. (1981). Conventional chemical fixations induce artifactual swelling of the dolipore septa. Exp Mycol 5, 167-172.

Howard, R. J. \& O'Donnell, K. L. (1987). Methodological review: freeze substitution of fungi for cytological analysis. Exp Mycol $11,250-269$.

Jersild, R., Mishkin, S. \& Niederpruem, D. J. (1967). Origin and ultrastructure of complex septa in Schizophyllum commune development. Arch Mikrobiol 57, 20-32.

Kapteyn, J. C., Montijn, R. C., Dijkgraaf, G. J. P. \& Klis, F. M. (1994). Identification of $\beta$-1,6-glycosylated cell-wall proteins in yeast and hyphal forms of Candida albicans. Eur J Cell Biol 65, 402-407.

Kapteyn, J. C., Montijn, R. C., Vink, E., De la Cruz, J., Llobell, A., Douwes, J. E., Shimoi, H., Lipke, P. N. \& Klis, F. M. (1996). Retention of Saccharomyces cerevisiae cell wall proteins through a phosphodiester-linked $\beta-1,3-/ \beta-1,6$-glucan heteropolymer. Glycobiology 6, 337-345.

Khan, S. R. \& Kimbrough, J. W. (1982). A re-evaluation of the basidiomycetes based upon septal and basidial structures. Mycotaxon 15, 103-120.

Lu, C. F., Montijn, R. C., Brown, J. L., Klis, F. M., Kurjan, J., Bussey, H. \& Lipke, P. N. (1995). Glycosyl phosphatidylinositol-dependent 
cross-linking of $\alpha$-agglutinin and $\beta$-1,6-glucan in the Saccharomyces cerevisiae cell wall. J Cell Biol 128, 333-340.

Lu, H. \& McLaughlin, D. J. (1991). Ultrastructure of the septal pore apparatus and early septum initiation in Auricularia auriculajudae. Mycologia 83, 322-334.

McLaughlin, D. J., Frieders, E. M. \& LU, H. (1995). A microscopist's view of heterobasidiomycete phylogeny. Stud Mycol 38, 91-109.

Marchant, R. \& Wessels, J. G. H. (1974). An ultrastructural study of septal dissolution in Schizopbyllum commune. Arch Mikrobiol 96, 175-182.

Markham, P. (1994). Occlusions of septal pores in filamentous fungi. Mycol Res 98, 1089-1106.

Mayfield, J. E. (1974). Septal involvement in nuclear migration in Schizophyllum commune. Arch Mikrobiol 95, 115-124.

Montijn, R. C., Van Rinsum, J., Van Schagen, F. A. \& Klis, F. M. (1994). Glucomannoproteins in the cell wall of Saccharomyces cerevisiae contain a novel type of carbohydrate side chain. J Biol Chem 269, 19338-19342.

Moore, R. T. (1977). Dolipore disjunction in Antromycopsis broussonetiae Pat. Exp Mycol 1, 92-101.

Moore, R. T. (1985). The challenge of the dolipore/parenthesome septum. In Developmental Biology of Higher Fungi, pp. 175-212. Edited by D. Moore, L. A. Casselton, D. A. Wood \& J. C. Frankland. Cambridge: Cambridge University Press.

Moore, R. T. (1996). The dolipore/parenthesome septum in modern taxonomy. In Rhizoctonia species: Taxonomy, Molecular Biology, Ecology, Pathology and Disease Control, pp. 13-35. Edited by B. Sneh, S. Jabaji-Hare, S. Neate \& G. Dijst. Dordrecht: Kluwer.

Moore, R. T. \& Patton, A. M. (1975). Parenthesome fine structure in Pleurotus cystidiosus and Schizophyllum commune. Mycologia 67, 1200-1205.

Muller, M. \& Moor, H. (1984). Cryofixation of thick specimens by high-pressure freezing. In Science of Biological Specimen Preparation, pp. 131-138. Edited by J. P. Revel, T. Barnard \& G. H. Haggings. Chicago: SEM Inc., AMF O'Hare.

Múler, M., Marti, T. \& Kriz, S. (1980). Improved structural preservation by freeze substitution. In Electron Microscopy 1980, pp. 720-721. Edited by P. Brederoo \& W. de Priester. Amsterdam: North Holland Publishing Company.

Muller, W. H., Van der Krift, T. P., Knoll, G., Smaal, E. B. \& Verkleij, A. J. (1991). A preparation method of specimens of the fungus Penicillium chrysogenum for ultrastructural and immunoelectron microscopical studies. J Microsc 169, 29-41.

Muller, W. H., Van Aelst, A. C., Van der Krift, T. P. \& Boekhout, T. (1994). Scanning electron microscopy of the septal pore cap of the basidiomycete Schizophyllum commune. Can J Microbiol 40, 879-883.

Muller, W. H., Van Aelst, A. C., Van der Krift, T. P. \& Boekhout, T. (1995). Novel approaches to visualize the septal pore cap. Stud Mycol 38, 111-117.

Müler, W. H., Stalpers, J. A., Van Aelst, A. C., Van der Krift, T. P. \& Boekhout, T. (1998). Field emission gun-scanning electron microscopy of septal pore caps of selected species in the Rhizoctonia s. I. complex. Mycologia 90, 170-179.

Orlovich, D. A. \& Ashford, A. E. (1994). Structure and development of the dolipore septum in Pisolithus tinctorius. Protoplasma 178, 66-80.
Patrignani, G., Pellegrini, S. \& Gerola, F. M. (1984). Differences in septal pore apparatus ultrastructure of Tremella mesenterica. Caryologia 37, 77-86.

Read, N. D. \& Beckett, A. (1996). Ascus and ascospore morphogenesis. Mycol Res 100, 1281-1314.

Reynolds, E. S. (1963). The use of lead citrate at high $\mathrm{pH}$ as an electron opaque stain in electron microscopy. J Cell Biol 17, 208-212.

Shinji, Y., Shinji, E. \& Mizuhira, V. (1975). A new electron microscopic histochemical staining method: demonstration of glycogen particles. Acta Histochem Cytochem 8, 139-144.

Shinji, E., Shinji, Y. \& Mizuhira, V. (1976). Histochemical study of a dermatophyte under an electron microscope: Trichophyton mentagrophytes cell wall. Acta Histochem Cytochem 9, 292-305.

Sitia, R. \& Meldolesi, J. (1992). Endoplasmic reticulum : a dynamic patchwork of specialized subregions. Mol Biol Cell 3, 1067-1072.

Spurr, A. R. (1969). A low-viscosity epoxy resin embedding medium for electron microscopy. J Ultrastruct Res 26, 31-43.

Studer, D., Michel, M., Wohlwend, M., Hunziker, E. B. \& Buschmann, M. D. (1995). Vitrification of articular cartilage by high-pressure freezing. J Microsc 179, 321-332.

Suh, S.-O., Hirata, A., Sugiyama, J. \& Komagata, K. (1993). Septal ultrastructure of basidiomycetous yeasts and their taxonomic implications with observations on the ultrastructure of Erythrobasidium hasegawianum and Sympodiomycopsis paphiopedili. Mycologia 85, 30-37.

Thielke, Ch. (1972). Die Dolipore der Basidiomyceten. Arch Mikrobiol 82, 31-37.

Tsuneda, A., Murakami, S., Sigler, L. \& Hiratsuka, Y. (1993). Schizolysis of dolipore-parenthesome septa in an arthroconidial fungus associated with Dendroctonus ponderosae and in similar anamorphic fungi. Can J Bot 71, 1032-1038.

Tu, C. C. \& Kimbrough, J. W. (1978). Systematics and phylogeny of fungi in the Rhizoctonia complex. Bot Gaz 139, 454-466.

Van der Valk, P., Marchant, R. \& Wessels, J. G. H. (1977). Ultrastructural localization of polysaccharides in the wall and septum of the basidiomycete Schizophyllum commune. Exp Mycol 1, 69-82.

Van der Walt, J. P. \& Von Arx, J. A. (1985). Use of ultrastructural characters in yeasts systematics. $S$ Afr Sci 81, 156-159.

Venable, J. H. \& Coggeshall, R. (1965). A simplified lead citrate stain for use in electron microscopy. J Cell Biol 25, 407-408.

Wessels, J. G. H. \& Marchant, R. (1974). Enzymatic degradation of septa in hyphal wall preparations from a monokaryon and a dikaryon of Schizophyllum commune. J Gen Microbiol 83, 359-368.

Wilsenach, R. \& Kessel, M. (1965). On the function and the structure of the septal pore of Polyporus rugulosus. J Gen Microbiol 40, 397-400.

Wösten, H. A. B., Moukha, S. M., Sietsma, J. H. \& Wessels, J. G. H. (1991). Localization of growth and secretion of proteins in Aspergillus niger. J Gen Microbiol 137, 2017-2023.

Received 22 December 1997; revised 5 March 1998; accepted 13 March 1998. 